\title{
Statement of Congratulations on the occasion of IJTCVS gaining recognition by PubMed Central
}

\author{
Channabasavaraj S. Hiremath ${ }^{1}$ (D)
}

Received: 15 November 2020 / Revised: 21 November 2020 / Accepted: 30 November 2020 / Published online: 2 January 2021

(C) Indian Association of Cardiovascular-Thoracic Surgeons 2021

It brings immense delight and pride to every member and well-wisher of the Indian Association of CardiovascularThoracic Surgeons to know of the recent and widely anticipated development — of our Indian Journal of Thoracic and Cardiovascular Surgery being indexed on PubMed Central ${ }^{\mathrm{TM}}$. This recognition for upholding scientific prowess with integrity is the beginning of yet another journey towards sustenance and development.

Obtaining recognition and membership to a scholarly repository such as this, being curated under the aegis of the National Library of Medicine which has resolved to make PubMed the premier source and widely accessible for credible biomedical learning resources [1] is a testament to the much needed effort to separate the original from the cloned. In the times of open access publishing, it has become integral to preserve, defend and protect the integrity of scientific literature published hitherto and forward, whilst ensuring that researchers have access to trustworthy and credible resources to accelerate the wheels of science.

The IJTC as we know it has served to uphold prudent academic and scientific research practices in the subspecialties of cardiothoracic surgery over the last nearly 4 decades. Beginning its genesis with one annual issue in 1982, the journal now publishes 4 regular quarterly issues in addition to special issues across the subspecialties, encapsulating state-of-the-art research and clinical findings undergoing stringent peerreview process to ascertain quality, integrity and honor of science (https://iacts.org/content/indian-journal-cardiovascularthoracic-surgery).

This success would have remained a distant dream if not for the erudite vision and stewardship of the Editors-in-Chief

Channabasavaraj S. Hiremath

hiremath.cs@sssihms.org.in

1 Department of Cardiothoracic \& Vascular Surgery, Sri Sathya Sai Institute of Higher Medical Sciences, EPIP Area, Whitefield, Bengaluru 560066, India till date-Dr. Solomon Victor, Dr. Amit Banerjee, Dr. Jayant Kharbase, Dr. Sampath Kumar, Dr. Krishna Iyer and the incumbent, Dr. Om Prakash Yadava under whose leadership we have seen the light of this recognition.

The incredible work being done in our subcontinent under less-than optimal conditions, nevertheless with comparable results, fails to catch the glimpse of the global community even today, 20 years after the siren was sounded [2] because we as a community have not taken interest and initiative to publish the hard work being carried out with ingenuity. I hope this unique achievement encourages the future generations to enlist this cause with priority.

Knowledge discovered collectively, and wisdom rediscovered individually, has been the edifice on which meaningful scientific collaboration and dissemination of subject matter has made this journey worthwhile and appealing to keep the process going and growing in time.

May the journal continue to be blessed with the unconditional benefaction and continued participation of all the authors, reviewers and the community at large - all of whom have played an active role in the continued success of this institution. In this journey of continued excellence, I hope that the IJTC makes its digital footprint well-acquainted through our Association's web-space.

Kudos to the editorial team and board for their tireless efforts in reaching this mantle of continued excellence!

With best wishes for the future and warm regards,

\section{References}

1. Williamson PO, Minter CIJ. Exploring PubMed as a reliable resource for scholarly communications services. J Med Libr Assoc. 2019;107:16-29.

2. Kumar AS. Redeeming our pride. Indian J Thorac Cardiovasc Surg. 2000;16:1-1.

Publisher's note Springer Nature remains neutral with regard to jurisdictional claims in published maps and institutional affiliations. 